\title{
The Rise of Pop-Up Retail: Investigating the Success of Experiential Design within Pop-Up Stores
}

\author{
Cindy Chen and Genesis Okken \\ University of Florida
}

Faculty Mentor: Genesis Okken, Department of Interior Design

\begin{abstract}
The purpose of this paper is to explore design factors behind successful pop-up shops and how design elements in these environments can enhance the consumer experience. Since pop-up shops are defined as "impermanent" environments, the connection between the consumer experience and design elements such as colors, lighting, materiality, form, and layout can have a meaningful impact in raising brand awareness and potentially influence sales. This exploratory and qualitative research collected data based on direct observations of six pop-up retail stores in the New York City. This study provides better insight to designers and companies on the importance of design strategies within environments in this quickly growing industry to create memorable experiences for consumers.
\end{abstract} identity

Keywords: Pop-up shops, color, lighting, form, materiality, retail, experiential design, brand

\section{Introduction}

A new and exciting retail sector known as "pop-up shops" is shifting the traditional "bricks and mortar' retail store experience to a highly engaging, temporal shopping experience in distinctive environments. The connection between consumer experience and design elements, specifically color, light, materiality, form, and layout, in this impermanent environment provides insights for professional growths to designers. The physical design produced by the use of these elements can influence the communication of brand identity and enhance consumer experience. This study explores the following questions: 1) Based on observational data in notable case studies, how are design elements communicating brand identity selected pop-up shops?, and 2) What can designers learn from these cases about creating a holistic experience for consumers?

\section{Literature Review}

The idea of pop-up, or temporary, stores is to provide a unique and unexpected shopping experience for consumers. The success of pop-up shops depends on a strong concept to promote the brand identity, a well-designed interior, and creating an extravagant experience for 
consumers (Haas \& Schimdt, 2016). In the article, The Magic of Pop-Up Shop Marketing, the director of Shopify expresses pop-up shops as "high-touch experiences" and how they believe this new phenomenon can be part of any brand's journey to attract consumers and increase store profit (Steimer, 2017). Due to the limited duration of operation, pop-up shop environments push the boundaries of design with innovative experiences for the consumers.

\section{Typology of Pop-Up Shops}

A pop-up shop typically remains open for a limited time, which can range from a week up to one year (Pomodoro, 2013). In Pomodoro (2013), four conceptual categories are introduced to help identify pop-up shops. These include concept stores, community stores, test stores, and sustainable stores. The four categories established by Pomodoro (2013) are used as a lens to help identify characteristics in the present study's case selections.

concept stores. A 'concept store' pop-up often focuses on a new collection or limitededition products to increase brand awareness. These stores are designed to work around the products and generate a memorable experience for consumers to better connect with the brand. In this type of pop-up store, the focus of how the elements of design are utilized is centered on creating a coherent visual brand identity.

community stores. A pop-up shop classified as a 'community store' typically ranges from a day to ten days. The purpose of this typology is to increase the relationship between consumer and brand through a sense of belonging to a brand community. The key strategies to enhance "consumer brand experience" in a community pop-up shop is to offer social events and themed night events (Pomodoro, 2013). According to Pomodoro (2013), the atmosphere should evoke a glamorous and sociable environment to increase the opportunity of memorable experience and social gatherings.

test- stores. Many startup businesses and e-commerce companies are shifting into the pop-up industry to test new brands and product lines. This typology is utilized as a market observational tool. Companies starting in new markets use this method to observe metrics like consumer behaviors, number of visitors, and the volume of sales. Retail design primarily focuses on promoting the store products, providing better customer service and often includes an "interactive tool" to get consumer feedback.

sustainable stores. As people are becoming more aware of environmental issues and human labor in production, eco-sustainable products have been a growing trend. Fashion companies that 
emphasize sustainability are typically high-end and luxurious as it targets slow fashion. Using high-quality materiality and controlling overproduction is how sustainable stores attract their consumers through the sense of emotion and touch. It would be expected to find these sustainable values embodied in the physical design to maintain an authentic brand identity.

\section{The Effect of Color and Light in Experiential Design}

To enhance the pop-up retail experience, color and light are significant design elements to brand the store identity and create an appealing atmosphere for consumers. According to (Calienes, Gilfilen, \& Portillo, 2016), cues of color and light can "enhance both visual store design and product display while also influencing the customers' sense of experience.

Specifically, color can draw the shopper into a space. The visuals of a store and product displays signify clues of store brand and a way to attract consumers. By "creating a moment" and holistic experience, it appears to influence positive consumer reactions, raise brand awareness, and potentially influence sales (Pomodro, 2013). As pop-up shops are increasing in popularity within the retail market, it is important to investigate the potential relationship of how color and light applications can increase brand awareness and shoppers' experience in retail design. Color depends on the intensity of light; therefore this affects the display of interiors and products (Kutlu, Manav, \& Klanc, 2013).

One of the benefits of temporary installation is the ability to focus on the brand concept in a cost-effective space. Because pop-up shops are relatively small, designers have more freedom to design a trendy space and push the boundaries of integrating design elements to create an area of emphasis. According to Kumar (2017), color is an effective tool to manipulate when creating a brand and selling a product because it impacts the consumer's first impression and influences their spending (Kumar, 2017). The correct illuminance in a store can entice people to enter, better promote the merchandise, and communicate the brand identity (Kutlu, Manav, \& Klanc, 2013). This supports the understanding that design elements need to be strategically utilized to maximize the attention for the brand and consumer experience. 


\section{Methodology}

This case study follows a similar approach used by Pomodro (2013), but with the intent of exploring a deeper understanding of design elements within this context. In Pomodoro's (2013) explorative and qualitative approach, six temporary stores were selected in one region. Through the author's observation, the study analyzed specific areas of the physical store and how the brand concept of each store influenced the design approach to creating a holistic experience for consumers. The present study based its methodology on Pomodoro (2013) study and collected qualitative data based on direct observations of six temporary retail stores in the New York City region (Figure 1.1). Case selections were made based on their inclusion within notable trade publications within the architecture and design industry (Figure 1.2).

\begin{tabular}{|c|c|c|c|}
\hline STORE & DURATION & LOCATION & $\begin{array}{c}\text { TYPE OF } \\
P O P \text { P S T ORE }\end{array}$ \\
\hline The Arrivals & $\begin{array}{l}\text { October } 05,2019 \\
\text { Febrary } 28,2020\end{array}$ & SoHo, NYC & Concept Store \\
\hline Mejuri X Vault & $\begin{array}{l}\text { November 23, } 2019 \\
\text { December 22, } 2019\end{array}$ & Chelsea, NYC & Concept Store \\
\hline Misha Nonoo & $\begin{array}{c}\text { September 01, } 2019 \\
\text { December 28, } 2019\end{array}$ & SoHo, NYC & $\begin{array}{l}\text { Test Store } \\
\text { Sustainable Store }\end{array}$ \\
\hline $\begin{array}{l}\text { Refinery } X \\
\text { Amazon }\end{array}$ & $\begin{array}{l}\text { December 05, } 2019 \\
\text { December 15,2019 }\end{array}$ & SoHo, NYC & Community Store \\
\hline Self- Portrait & $\begin{array}{c}\text { August 12, } 2019 \\
- \\
\text { December } 22,2019\end{array}$ & SoHo, NYC & $\begin{array}{l}\text { Test Store } \\
\text { Sustainable Store }\end{array}$ \\
\hline Tupperware & $\begin{array}{l}\text { November 15, } 2019 \\
\text { December 22, } 2019\end{array}$ & Soho, NYC & $\begin{array}{l}\text { Test Store } \\
\text { Sustainable Store }\end{array}$ \\
\hline
\end{tabular}

Figure 1.1. Six Pop-Up Cases

\begin{tabular}{|l|l|l|}
\hline $\begin{array}{l}\text { Sources for } \\
\text { Successful } \\
\text { Pop-Up Store Cases }\end{array}$ & $\begin{array}{l}\text { Case Studies } \\
\text { Information for } \\
\text { Observational Data }\end{array}$ \\
Cool Hunting.com & The Arrivals & $\begin{array}{l}\text { Store Background } \\
\text { Color }\end{array}$ \\
Surfacemag.com & Rejuri Vault & $\begin{array}{l}\text { Lighting } \\
\text { Materiality } \\
\text { WWD.com }\end{array}$ \\
Travelandleisure.com & Self-Portrait & $\begin{array}{l}\text { Layout } \\
\text { Display }\end{array}$ \\
& Tupperware & $\begin{array}{l}\text { Experiential Factor } \\
\text { Branding }\end{array}$ \\
\hline
\end{tabular}

Figure 1.2. Chart indicating the Methodology Process 
Key design elements including color, lighting, materiality, form, and layout were all considered to develop the observational form used within this study. This data, while limited to one observer, helped inform analysis of the physical retail design of these successful pop-up stores. An observational form was constructed into four parts for each pop-up store. Part one briefly describes the typology of pop-up shop, duration of opening, location, and statement of the store's concept and goals.

The second part captures the overall design elements of color, lighting, materials, and store layout. The observational instrument included the collection of photographs as visual support. Color was analyzed based on the general color scheme, variety of hues, contrast, and saturation of colors. Lighting design was described based on color temperature, layers of lighting, types of light fixtures, and utilization of natural lighting. The use of materiality and texture design was described along with types of furniture and display units incorporated.

Part three explains and describes any experiential factor incorporated in the pop-up shop. It included an explanation of what areas of the store drew the most attention. These areas were then specified in the layout.

The last part of the observational instrument briefly explained how the spatial design connected with the store design. This section also looked at how social media platforms, specifically Instagram, played a role in branding their products.

\section{Findings}

\section{The Arrivals}

The Arrivals is an example of a concept store. The purpose of this temporary store is to launch the FW Collection titled, "The Out There Lab". This concept provides a playful and performative temporary space to feature three distinct zones of extreme microclimates in order to encourage consumers to go outside wearing The Arrivals garments. Throughout the store design, it uses translucent polycarbonate partitions to divide the three zones - rainforest, desert, and snow (Figure 2.1). The polycarbonate partitions act as a structure that brings a sense of a modern gallery environment. It is well contrasted with the general, cool lighting from the suspended linear LED lighting fixture hanging from the exposed ceiling conditions. Different types of linear LED lighting are used throughout the store as a functional and decorative element (Figure 2.2). 


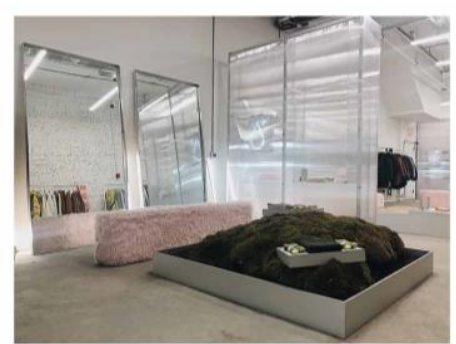

(1) The Rainforest Zone

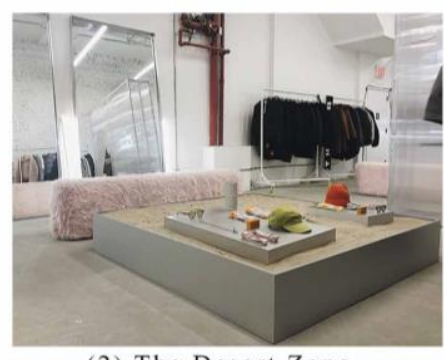

(2) The Desert Zone

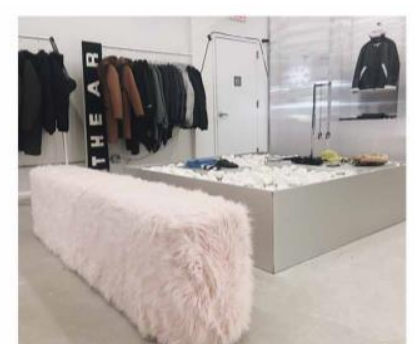

(3) The Snow Zone

Figure 2.1. Each zone contains a large square display. The rainforest zone is filled with live mosses. The desert zone is filled with desert sand to express the sun and dryness The snow zone is filled with heavy white pebbles. ${ }^{1}$
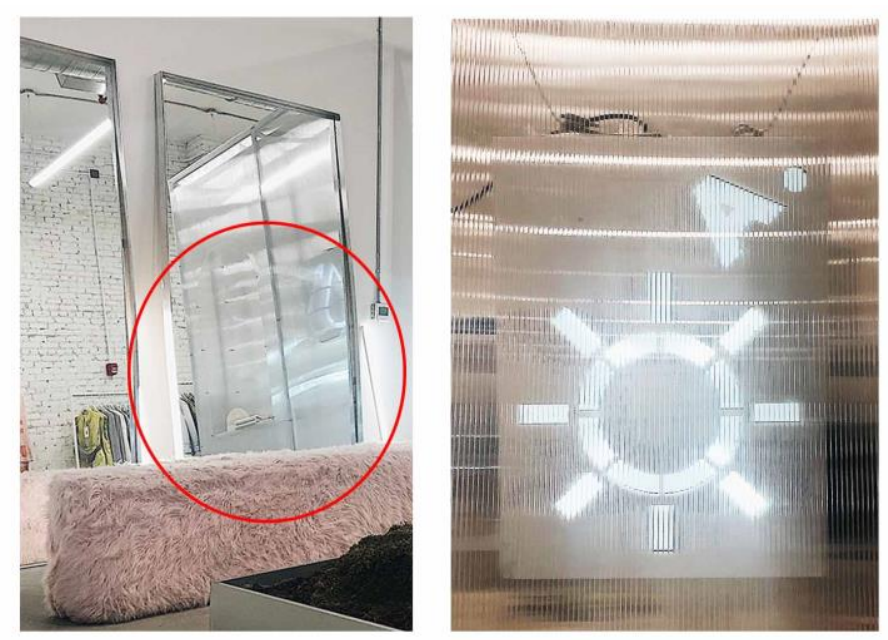

Figure 2.2. Every mirror is flanked by linear LED fixtures (left). ${ }^{1}$ Example of LED lighting display of desert zone icon (right) ${ }^{1}$.
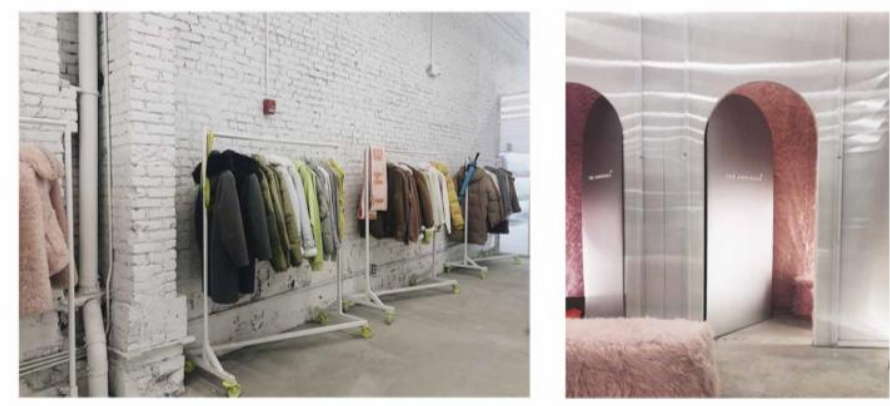

Figure 2.3. Product collection showcasing the soft pink and neon green (left). ${ }^{1}$ The cohesive design is carried along to the changing rooms decorated with the soft pink faux fur (right). ${ }^{1}$ 
Surprisingly, the rationale behind the color planning decisions appears to be influenced by the product collection instead of the white and black logo of the brand. The colors of soft pink and neon green bring a strong contrast to the white space (Figure 2.3). Despite the focus on the product line, this pop-up shop emphasizes a strong component of branding through the cohesiveness of design between the physical environment, brand identity, and products.

\section{Mejuri Vault}

Another example of a 'concept store' is the Mejuri Vault pop-up store located in Chelsea, New York. The purpose of this pop-up store is to celebrate Mejuri's fifth anniversary and launch its limited-edition tarot collection. The concept of the Vault pop-up store is influenced by astrology with three iconic collections of zodiac, tarot, and diamond. This immersive pop-up space is designed into three zones for consumers to explore the collection in a maze-inspired experience. The walls are constructed with metal wire covered with ochre-colored paper material. Upon entering, the first zone is a gallery space presenting the twelve zodiac signs (Figure 3.1). The space communicated a whimsical atmosphere with the help of dim, warm lighting. The tarot zone offers a bright, circular space filled with flamboyant layered tissues, and the four symbols of tarot - moon, sun, star, and strength hanging from the ceiling (Figure 3.2). The center displays a fun experiential opportunity for consumers to spin the tarot wheel. This activity can influence consumer purchases based on what they landed on the wheel.

Before approaching the sales area, the diamond zone reveals a glamorous and reflective area. The yellow curvilinear wall is covered with a holographic rainbow material crumbled into a diamond effect with mirrors attached to the front (Figure 3.3). The diamond zone communicates its last message by quoting "Diamond For Your Damn Self" on the concrete floor. This offers a moment of self-reflection by telling the consumers this is the time to reward yourself and be proud of who you are. The Mejuri pop-up store is a great example of connecting the elements of branding, product collection, and store design into an interactive experience for consumers (Figure 3.4). Unlike the other temporary retail stores examined, the Mejuri pop-up store offers a dim, warm-toned atmosphere, which visually enhances their best-selling gold jewelry. 


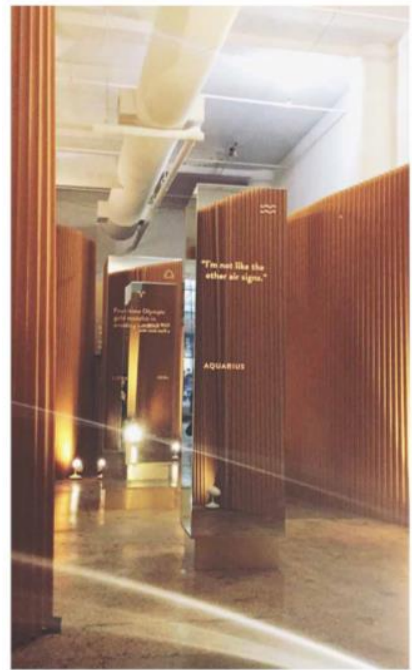

Figure 3.1. The zodiac zone with horoscope signs displayed on mirrors. ${ }^{1}$

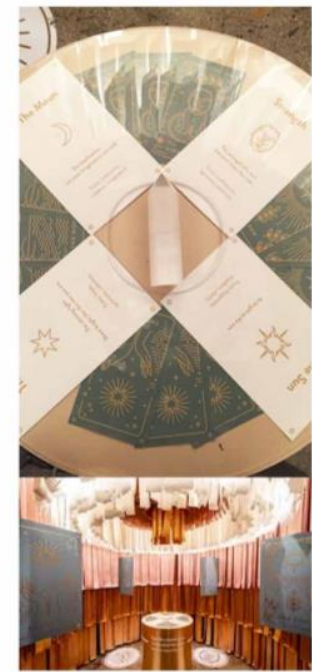

Figure 3.2. Tarot zone filled with colorful tissue. (Retrieved from https://mejuri.com/vault)

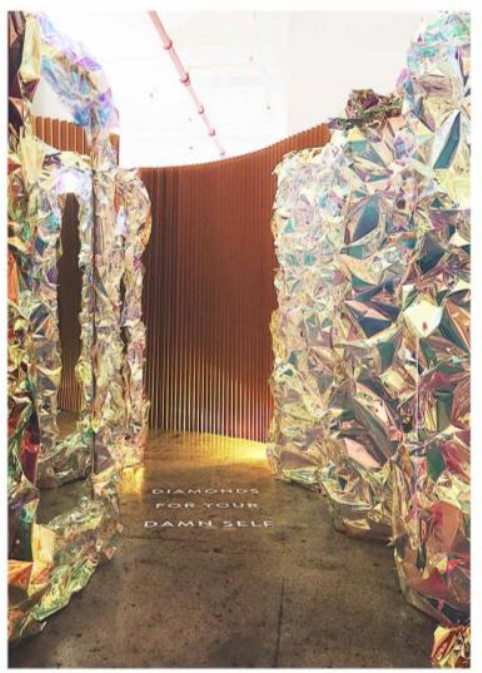

Figure 3.3. Diamond zone quoting "Diamond for your damn self." 1
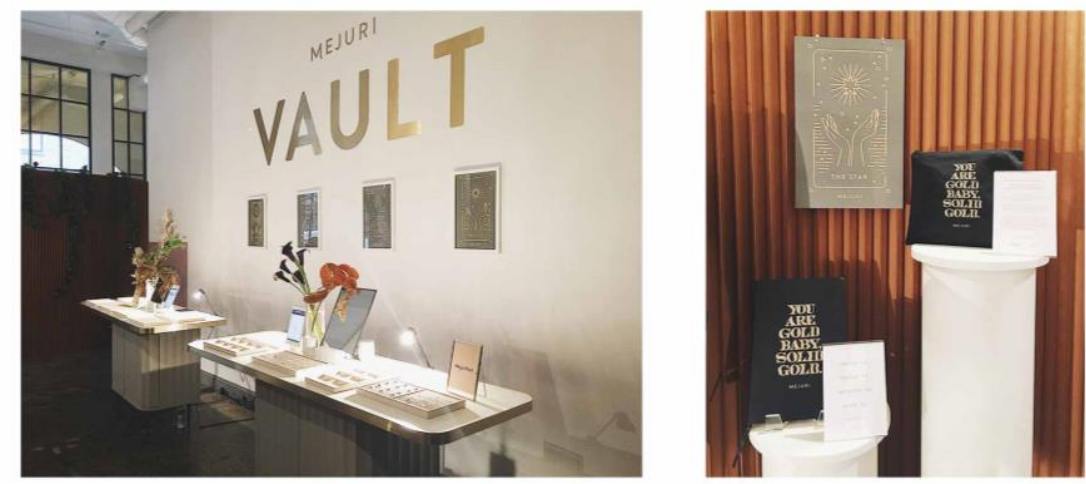

Figure 3.4. The sales area expresses a clean and minimalistic space. ${ }^{1}$

\section{Self-Portrait}

Self-Portrait is a British contemporary womenswear brand providing attainable fashion through sustainable, high-quality fabrics. The purpose of this pop-up store was to test the market in a new location and launch the limited-edition of the Autumn 19 Ready to Wear collection. Upon entering, an artistic lace installation of a tactile labyrinth offers an explorative experience before transitioning into the collection (Figure 4.1). The laces were inspired by Self-Portrait's dresses. Thin sheets of pink and white laces are layered and sewn into a curved metal rod to form a concentric circle. The installation includes color-changing LED lights of pink, yellow, and white. Another key design element is the use of exposed timber to create a more approachable entrance and balance the luxurious experience. The structure of the wood is used as a supporting detail to divide the space and serves as a functional element for the clothing rack (Figure 4.2). 

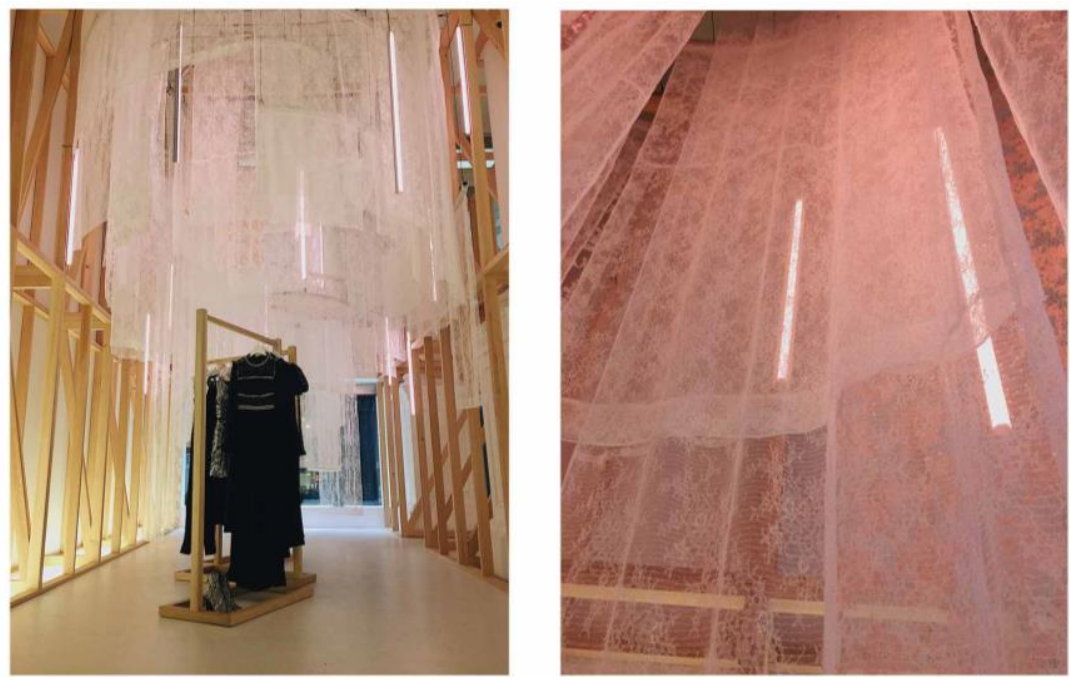

Figure 4.1. Self-Portrait installation with pink and white laces. Linear LED light fixture adding aesthetic to space. ${ }^{1}$

The wide stairs with the LED accent lighting add a welcoming transition going from a soft installation to entering a bright retail space. From the exterior, the windows are tinted in orange with two circular clear glass designs emphasizing the artistic installation and timber wood to grab the attention of people on the streets (Figure 4.3). As Self-Portrait is an eco-sustainable brand, the wood expresses sustainability and the installation of laces represents the high-quality nature of the brand. With its materiality and colors, it captures the sense of femininity and sophistication of the brand.

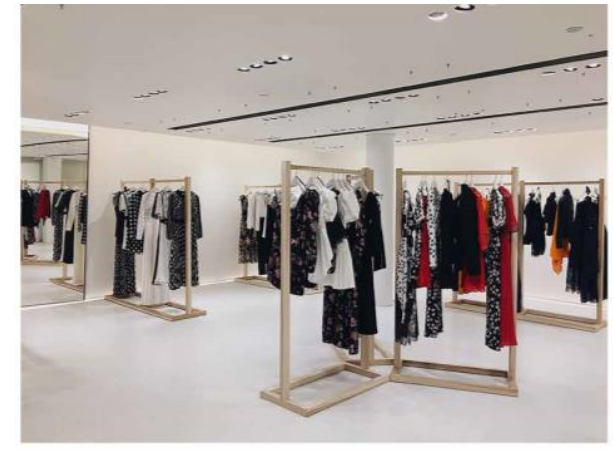

Figure 4.2. Cloth racks using timber wood. ${ }^{1}$

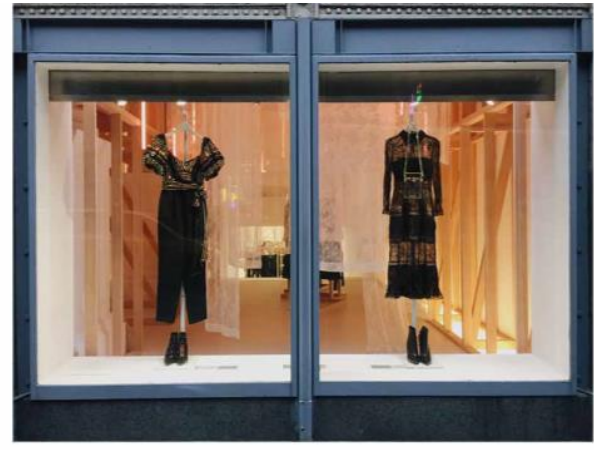

Figure 4.3. Exterior view of window peaking through the installation. ${ }^{1}$ 


\section{Refinery 29 X Amazon}

A collaboration with Refinery 29, Amazon Fashion, and Amazon Home held a ten-day pop-up store titled Deckled and Dazzled to present a live experience for 2019 holiday gift collection. As a community type store, daily events were held to allow consumers to socialize with famous influencers (Figure 5.1). The selections within the store were identified as "influencer - inspired picks" and emphasized a connection to social media. This emphasis was also highlighted in the incorporation of decorative areas also known as 'instagrammable moments' that were designated throughout the store (Figure 5.2). These areas provided the opportunity for consumers to market the brand by documenting their experiences on social media. Specifically, consumers could post an image using the hashtag \#FOUNDITONAMAZON, which was displayed on a golden plate in the center of the store (Figure 5.3).

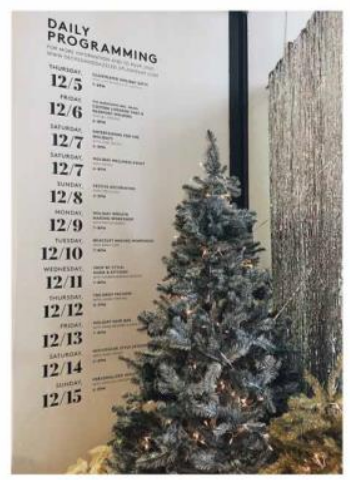

Figure 5.1. Display of social events offered at the pop-up store. ${ }^{1}$
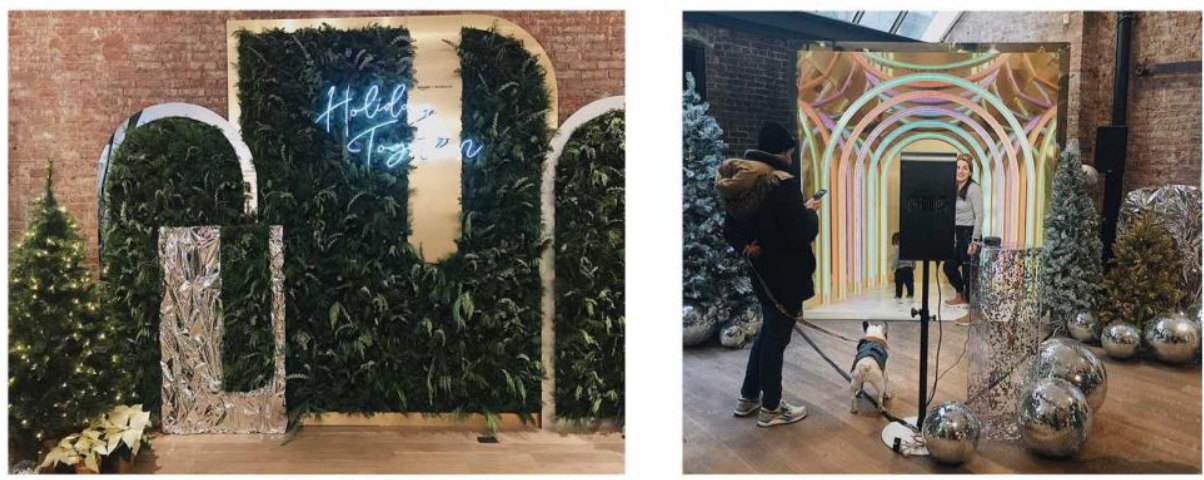

Figure 5.2. Instagrammable moment at the entrance (left) ${ }^{1}$ and another located at the back (right). ${ }^{1}$

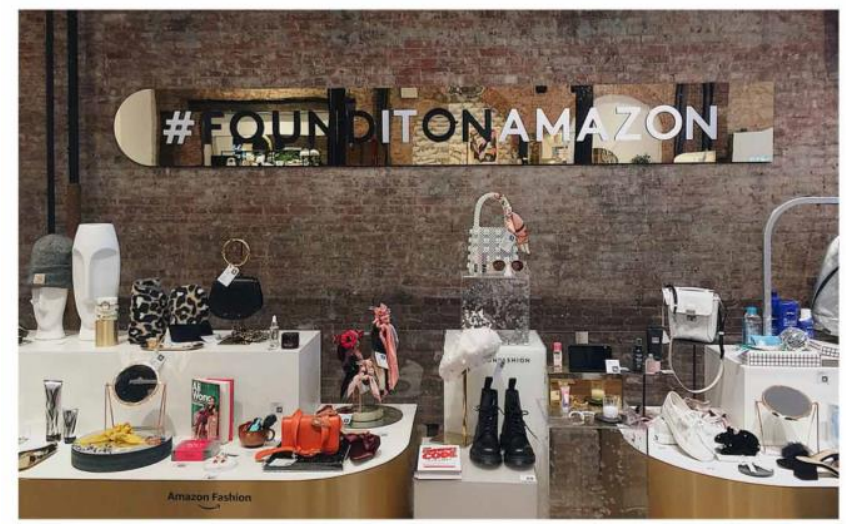

Figure 5.3. \#FOUNDITONAMAZON consumers are able to post instagrammable moments through social media using this hashtag. ${ }^{1}$
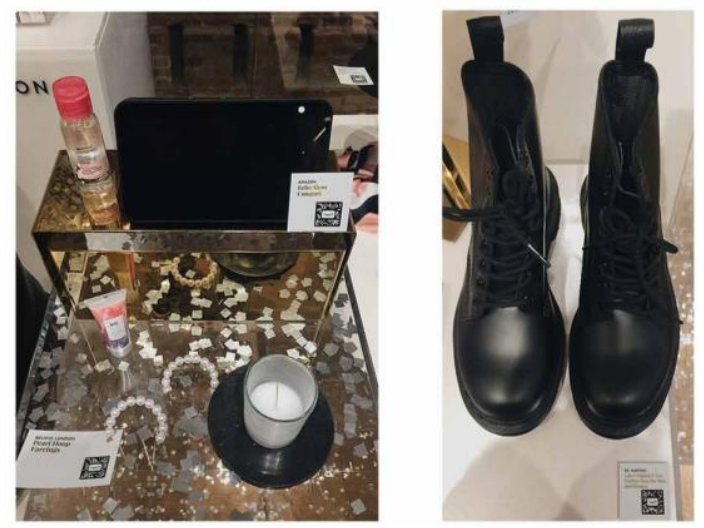

Figure 5.4. Example of scan and purchase concept with the QR Code displayed on the side. ${ }^{1}$ 
To enhance the experience, this collaboration offers the convenience of having purchases delivered home with a quick QR scan on your phone or Amazon app (Figure 5.4). Located across from the hashtag sign is a small coffee counter offering free drinks for consumers as they shopped around (Figure 5.5). This marketing technique enables consumers to stay longer and supports a more positive shopping experience. Overall, the store used holiday decorations and metallic materials to emphasize the holiday shopping focus of the pop-up. Track lighting fixtures were mainly used that provided strong general, white lighting to the space and supported the shopping environment. The store offered a welcoming environment that reinforced a sense of community through social interaction and unique shopping experiences.
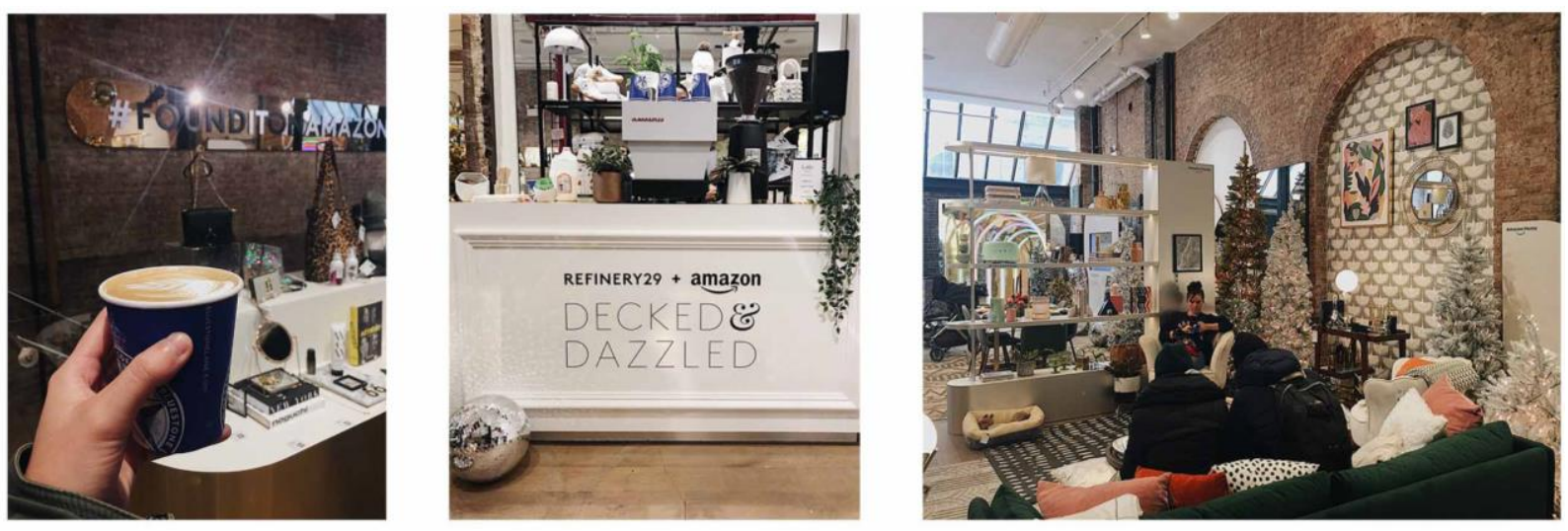

Figure 5.5 Café counter offering free hot drinks (left). ${ }^{1}$ Next to the café is a lounge area for consumers to wait for drinks and promote Amazon Home products (right). ${ }^{1}$

\section{Misha Nonoo}

Misha Nonoo, a luxury womenswear brand, opened its first test pop-up store in New York City. The brand focuses on empowering the female community, elegance, and sustainable products. The pop-up store features Misha Nonoo products and other high-end collaborations such as The Laundress and Sarah Flint. While this pop-up store does not offer any consistent interactive activities, the shopping experience was a pleasant process of exploring the brand and products. Special events and occasions such as yoga, meditation, flower masterclasses, and women's conference were held during specific days of the month that provide an exclusive social interaction to empower women. 
The store design appears to have a white and black minimalistic aesthetic as it reflects the Misha Nonoo products of a classic and chic style. The velvet upholstery of the furniture in the lounge enhances the experience of comfort and luxury (Figure 6.1). Inspirational quotes are placed throughout the store as a branding element and motivation for why consumers should purchase their products (Figure 6.2).
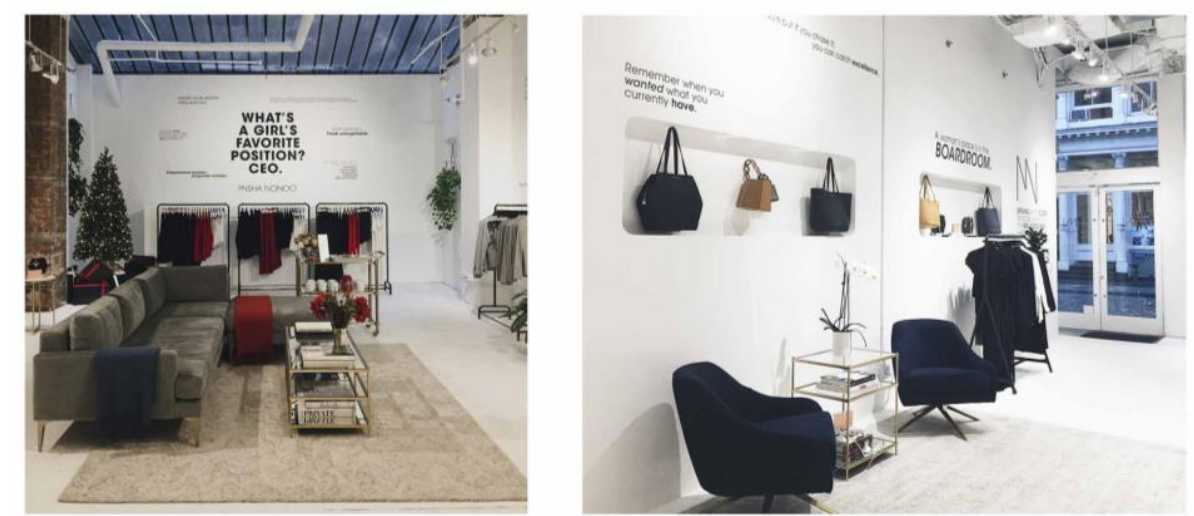

Figure 6.1. A view of lounge space. Furniture is carefully chosen to meet the standards of the brand with soft velvet fabric. ${ }^{1}$
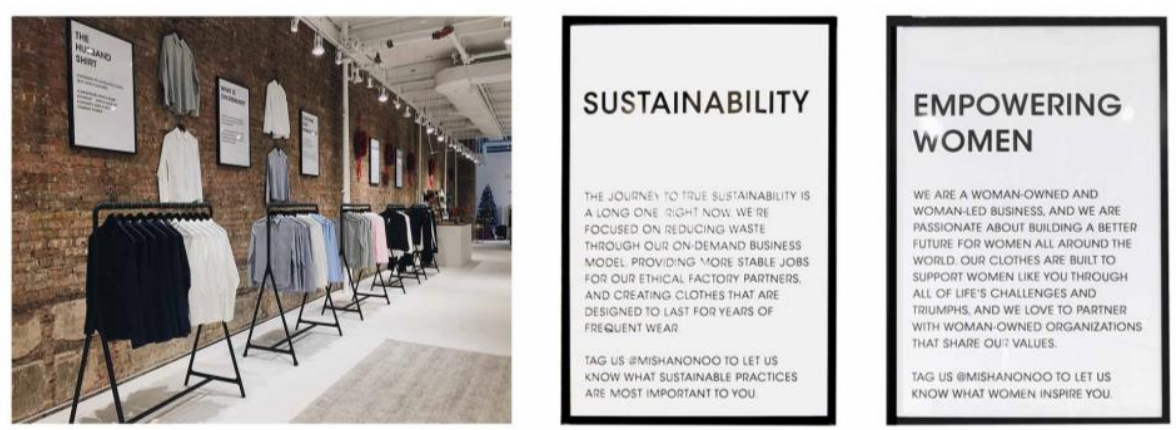

Figure 6.2. The minimalistic interior space with the hanging quotes on the brick. ${ }^{1}$

\section{TuppoSoho}

Another example of a test and sustainable type pop-up store is Tupperware, a brand that sells home products including storage containers and kitchen preparations. Honoring their 73rd anniversary, the company opened its first pop up store called TuppSoho to launch their new evolution of products over these years. The interior is filled with vivid, colorful displays. Each color has a different architectural form and is divided into zones where consumers can explore and take advantage of 'instagrammable' moments throughout the store (Figure 7.1). The green zone installation includes a cafe filled with colored LED lighting and greenery effects (Figure 7.2). 

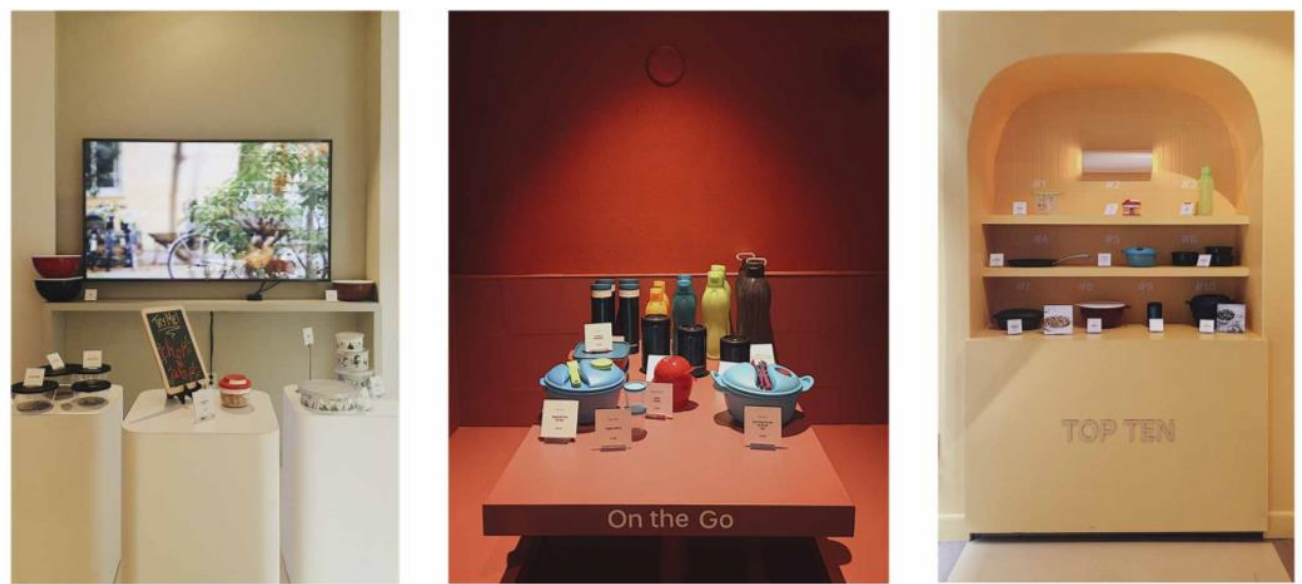

Figure 7.1. View of white, red, and yellow zones of TuppoSoho. ${ }^{1}$

Another engaging spot is the blue zone, designed for consumers to order products online before leaving (Figure 7.3). It includes a U-shape bench seat with several low tabletops for iPad displays. As consumers are waiting and exploring, the bolded question "Did You Know?" placed in the center of space integrates an interactive wall educating consumers about the history of Tupperware and to increase brand awareness.
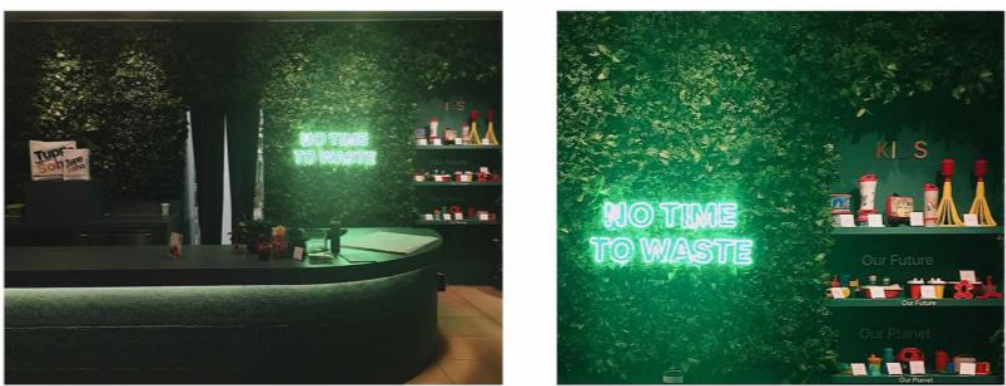

Figure 7.2. The green zone displays a quote, "No time to waste" emphasizing the importance of sustainability in Tupperware. ${ }^{1}$
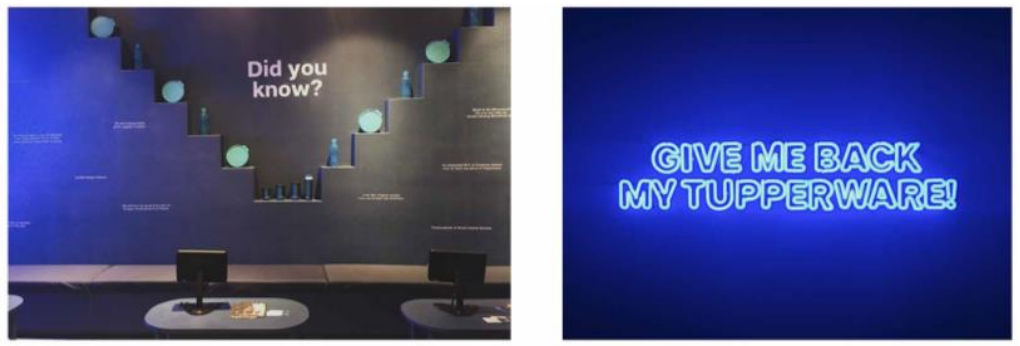

Figure 7.3. The blue zone displays a quote, "Give me back my Tupperware!" in LED lighting and offers an instagrammable moment. ${ }^{1}$ 


\section{Implications}

\section{Color and Light}

Based on the observational data, five out of six stores had a bright white color temperature for the overall store lighting. Mejuri Vault was the only store to use a warm-tone lighting, which was most likely influenced by the goal of emphasizing its product line. The space uses dramatic up-lighting from the floor to create a dream-like atmosphere as well as an emphasis on specific architectural elements. LED linear lighting and colored LED lighting was commonly used as a decorative element to attract attention. Stores like The Arrivals and Self-Portrait used linear LED light fixtures to enhance the aesthetics of the space. Colored LED lighting was used in stores such as Tupperware, Refinery X Amazon, and The Arrivals to highlight particular areas. For example, Tupperware blue and green LED lighting was used to focus on the brand's sustainable Tupperware products as Refinery X Amazon incorporates rainbow LED lighting in instagrammable areas.

In regards to the color design solutions, color selections for three out of the six stores were focused on the product collection rather than the brand. For example, The Arrivals garments used pops of soft pink and neon green. Consequently, the store's color palette complimented the product selection instead of keeping to the minimalistic concept of the main brand. These cases show the opportunity that impermanent environments create with experiences tailored to the products versus general branding.

\section{Materiality and Form}

To create an extravagant and immersive pop-up experience for consumers, four out of six companies tended to use an abundance of one material to form architectural features. Being a temporary entity by definition, each of the six pop-up stores studied seemed to choose costefficient materials that are easier to disassemble. Stores like The Arrivals, Mejuri Vault, and SelfPortrait have a unique and dramatic partition design to divide different zones. Some brands often use alternative materials to replicate an expensive look. For example, Mejuri Vault used yellow paper partition and strong warm light to represent gold and a holographic rainbow foil to represent diamonds. This strategy illustrates how materiality and form can add a vital characteristic to enhance the consumer experience. 


\section{Spatial Layout and Display Elements}

Based on this exploration, younger brands developing their brand concepts controlled the layouts into a few key zones. For example, The Arrivals, Mejuri Vault, and Self-Portrait all had a division of zones that are designed to have a modern, gallery-like experience. Meanwhile, the more established stores like Refinery x Amazon, Misha Nonoo, and Tupperware had free-flowing spatial layouts where consumers wandered throughout the space and transitioned from one space to another without guidance. Upon entering half of the pop-up stores, best-sellers and limitededition products are displayed in the front or center of the store. The pop-up stores utilized every surface to display some sort of product or artsy quote as an opportunity to enhance the brand.

\section{Conclusion}

This study presents the findings on six case studies focusing on how design elements are utilized in pop-up retail environments and enrich the communicated brand identity. Given the rise of this phenomenon, temporary stores rely heavily on communicating the brand identity through design and creating an appealing atmosphere to enhance the consumer experience. Based on the brand concept, these elements can be used creatively to articulate division of spaces, circulation pathways, or to emphasis particular areas. As pop-up stores are attracting consumers to a more experiential component of the retail design industry, it is valuable to capture the story of the brand and products to better utilize design elements to convey the message creatively.

Nevertheless, limitations to this study are similar to Pomodoro (2013) since the findings are limited to six pop-up stores in one particular region and restricted to observational data from one observer. The data from this observational approach may include personal perceptual and observational bias. There is potential to further investigate the pop-up industry on a larger scale with multiple observers and survey data to better capture the consumer perspective. It would also be interesting to investigate different regions such as comparing American and European regions. The strategies observed and discussed among these six cases start to help designers understand opportunities for developing successful and engaging pop-ups that support their respective typology goals and communication of their brand. As the retail market continues to evolve, designers are duty-bound to transform alongside it and innovate with creative design solutions. 


\section{References}

Calienes, E., Gilfilen, C., \& Portillo, M. (2016). Inside the Mind of the Millennial Shopper: Designing Retail Spaces for a New Generation. Interior Design .

Haas , S., \& Schmidt, L. (2016). What Drives The Success of Pop-Up Stores? . Technische Hochschule Wildau Technical University of Applied Science, 89-97.

Kumar, S. (2017). The Psychology of Colour Influences Consumers' Buying Behaviour - A Diagnostic Study. Business Management .

Kutlu, R., Manav , B., \& Klanc, R. (2013). Retail Design: Color-Light Influence on Brand IdentityImage Perception . World Applied Sciences Journal , 598-606.

[Photograph of The Vault pop-up store tarrot zone interior]. (n.d.) Retrieved from https://mejuri.com/vault

Pomodoro, S. (2013). Temporary Retail in Fashion System: An Explorative Study. Fashion Marketing and Management, 341-352.

Steimer, S. (2017, October 1). The Magic of Pop-Up Shop Marketing . Retrieved from American Marketing Association: https://www.ama.org/marketing-news/the-magic-of-pop-up-shopmarketing/

\footnotetext{
${ }^{\text {i }}$ Photograph taken by Author on Dec 2019
} 